ISSN: 0514-7336

DOI: http://dx.doi.org/10.14201/zephyrus201372153171

\title{
LA NECRÓPOLIS MUSULMANA DE VALDEHERRERA (CALATAYUD, ZARAGOZA): NUEVOS DATOS CRONOLÓGICOS SOBRE LA FUNDACIÓN DE CALATAYUD
}

\section{The Muslim necropolis of Valdeherrera (Calatayud, Zaragoza): New chronological information for the foundation of Calatayud}

\author{
J. Carlos SÁenz Preciado y Manuel Martín-Bueno \\ Dpto. de Ciencias de la Antigüedad. Facultad de Filosofía y Letras. Cl Pedro Cerbuna, 12. 50009 Zaragoza. \\ Correo-e: casaenz@unizar.es
}

Recepción: 3/07/2013; Revisión: 25/07/2013; Aceptación: 12/09/2013

BIBLID [0514-7336 (2013) LXXII, julio-diciembre; 153-171]

RESUMEN: Una de las novedades más importantes del recién iniciado proyecto de investigación en el yacimiento de Valdeherrera ha sido el descubrimiento de una necrópolis musulmana o maqbara de cronología emiral ubicada entre los restos de la ciudad celtíbero-republicana existente en el lugar. Dada la ausencia total de materiales islámicos en el yacimiento, este descubrimiento ha marcado un hito en la investigación histórica de la ocupación islámica del territorio y del origen de Qal'at Ayyub, confirmando lo que las fuentes escritas musulmanas narraban.

En este trabajo no pretendemos ofrecer una visión de conjunto ni un estudio exhaustivo de la maqbara descubierta, ya que los trabajos de excavación continúan y todavía no ha sido posible determinar su extensión. El fin último es dar a conocer su descubrimiento y aportar una secuencia cronológica que complete el vacío de información existente en este momento sobre el inicio de la presencia árabe en el valle medio del Jalón, donde se encuentra la ciudad de Qal'at Ayyud, que jugará un importante papel a lo largo de la Edad Media.

Palabras clave: Maqbara. Período emiral. Valle del Jalón. Muerte violenta.

ABSTRACT: One of the news more importantly of recent research project in Valdeherrera site has been the discovery of a Muslim necropolis; this maqbara dated in emiral period is located between the remains of the Celtiberian-Roman Republican city existing in the place. Given the total absence of Islamic materials here, this discover has marked a key in the historical investigation of the Islamic occupation of Qal'at Ayyub's territory and origin, confirming the Muslim written sources.

In this work we not aim to provide an overview or a comprehensive study of the discovered maqbara; the archaeological work continues and has not yet been possible to determine its extent. The ultimate goal is to publicize this discovery and provide a chronological sequence to fill the information gap existing at the moment of the start of the Arab presence in the middle valley of Jalon, where Qal'at Ayyud city played an important role throughout the Middle Age.

Key words: Maqbara. Emiral Period. Jalón Valley. Grave. Violent death. 


\section{Ubicación y contexto geográfico}

El yacimiento de Valdeherrera ${ }^{1}$ se sitúa a unos $4 \mathrm{~km}$ al so de Calatayud, junto a la carretera que conduce a Munébrega (C-202), en la margen izquierda del río Jiloca (Fig. 1). Ocupa un promontorio de escasa altura en el mismo ángulo formado por los valles del Jiloca y del Jalón, presentando una suave pendiente descendente N-S que se eleva ligeramente sobre las vegas circundantes y desde donde se domina a la perfección todo el entorno geográfico delimitado en la confluencia de ambos ríos, ofreciendo así una privilegiada visión de la Calatayud actual (Fig. 2).

Gracias a esta aventajada situación, este territorio siempre ha albergado asentamientos de gran importancia que lo estructuraron y jerarquizaron en algunos momentos: Segeda, Valdeherrera, el oppidum de la Calatayud celtibérica, en época romana Bilbilis Italica, Municipium Augusta Bilbilis y Qal'at Ayyub -actual Calatayud-, desde época musulmana hasta el presente. Las sucesivas campañas de prospección realizadas en el término de Valdeherrera y su entorno entre 2005 y 2008, continuadas de manera intermitente hasta la actualidad, ofrecen los siguientes porcentajes: materiales vinculados al Bronce final $(0,5 \%)$, época celtibérica $(38,5 \%)$, época republicana $(57 \%)$, época altoimperial $(2 \%)$ y época bajoimperial $(2 \%)$.

\footnotetext{
${ }^{1}$ Entre los años 2005-2009 se ha desarrollado un proyecto de investigación entre el Centro Ausonius de la Univ. Michel de Montaigne Bordeaux 3 y el Área de Arqueología-Grupo URBS del Dpto. de CC de la Antigüedad de la Univ. de Zaragoza, con la colaboración del Centre Littoral de Géophysique de la Univ. de La Rochelle; estos trabajos han sido codirigidos por los firmantes de este artículo. A partir de esa fecha las excavaciones han sido coordinadas desde la Univ. de Zaragoza dentro del proyecto MINICINN-HAR. 2008-03752: URBS II: Modelos edilicios y prototipos en la monumentalización de las ciudades de Hispania. Sobre las labores arqueológicas realizadas en Valdeherrera cf. Martín-Bueno, Krausz y Sáenz, 2009; Martín-Bueno y Sáenz, 2012, 2013; Krausz, Mathé y Druez, 2012.
}

Valdeherrera se ubica en uno de los puntos neurálgicos de la Celtiberia, en la confluencia del río Jiloca con el Jalón, dos de las principales vías naturales de la Antigüedad, ya que a través de ellas se producía la comunicación entre la Meseta, el valle del Ebro y la costa. Por ello, el desarrollo del asentamiento se verá favorecido por el cruce de caminos existente en su entorno: por el valle del Jiloca entre las dos ramas del Sistema Ibérico, a través de Daroca y las tierras de Teruel hasta el valle del Turia por el sureste hasta el litoral mediterráneo, y por el valle del Jalón, bien hacia el valle del Ebro o hacia la Meseta con su prolongación por el Henares, sin olvidar que a $9 \mathrm{~km}$ al NO desemboca en el Jalón el río Ribota, por cuyo valle se puede acceder fácilmente hacia el Sistema Ibérico, el Moncayo con su riqueza minera y la meseta soriana (Fig. 3).

\section{Introducción historiográfica ${ }^{2}$}

A pesar de la importancia de este yacimiento, especialmente en época celtibérica, han sido muy pocas las noticias que teníamos de su existencia,

${ }^{2}$ Una detallada revisión historiográfica de este yacimiento en Sáenz, J. C.: "Una revisión historiográfica de los estudios sobre la ciudad celtibérica de Valdeherrera", Saldvie, 13, e. p. 


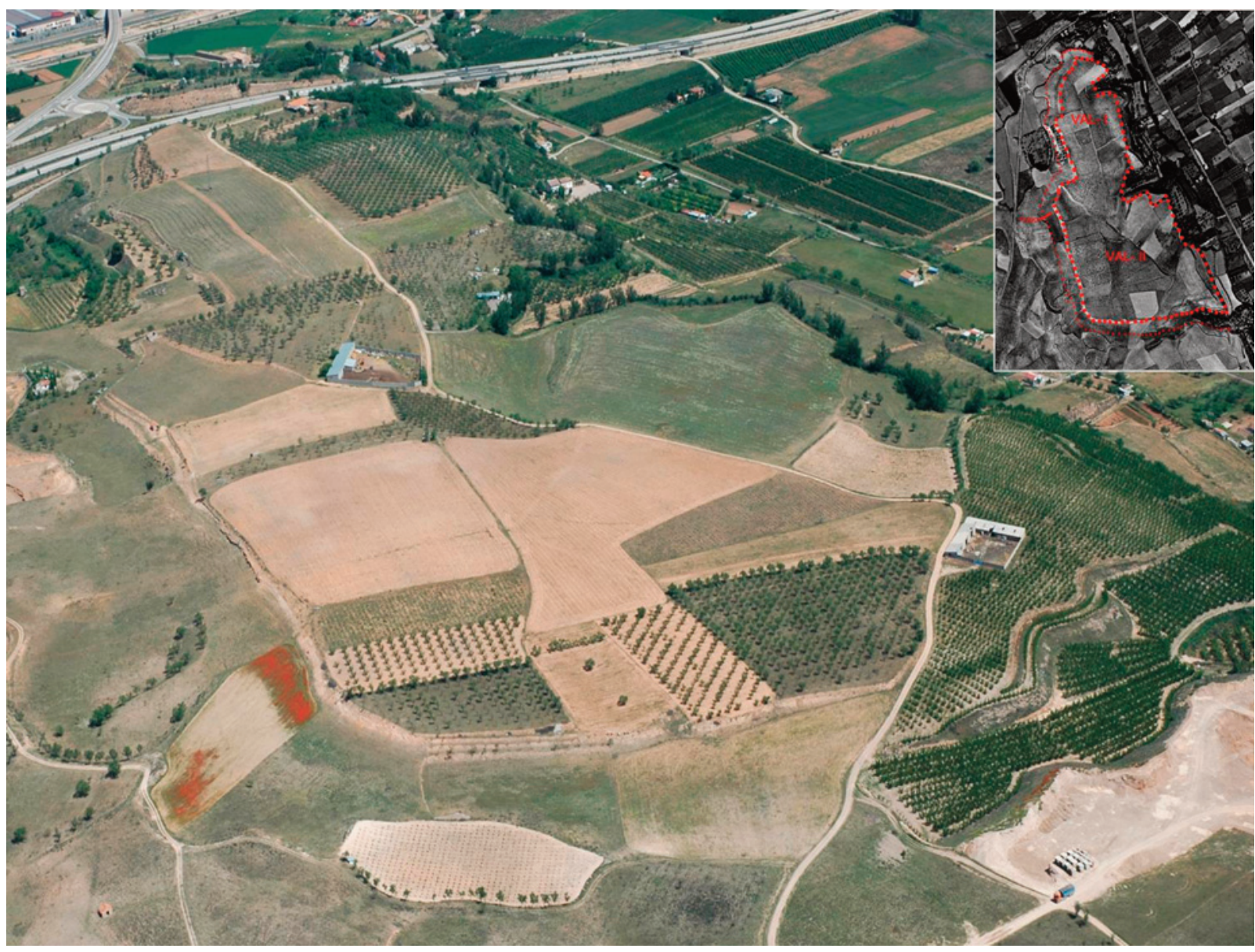

FIG. 2. Vista aérea de Valdeherrera desde el sur (fotog. F. Didierjean). Enmarcada la topografía del yacimiento en 1956 (USAF 1956 Hoja 437-29.746) con la delimitación del yacimiento y su foso.

debiéndose la primera mención escrita conocida al historiador local V. de la Fuente, quien publicó su existencia en 1880 en su obra Historia de la siempre augusta y fidelisima ciudad de Calatayud. Más tarde, otros historiadores locales como López Landa (1935: 71-72) y López Sampedro (1968: 147) hacen referencia al yacimiento en un intento de ubicar en él Platea, ciudad mencionada en los epigramas de $\mathrm{Marcial}^{4}$, sin dudar nunca de la ubicación de la Bilbilis indígena en otro lugar que no

${ }^{3}$ Hemos utilizado la ed. facsímil de esta obra publicada en 1994 por el Centro de Estudios Bilbilitanos de Calatayud.

${ }^{4}$ Marcial, Ep. IV.55.13: "Platea que resuena por su hierro rodeada por el Jalón que da temple a sus armas" y Ep. XII.18.11: "Boterdo y Platea, estos nombres, tan broncos tienen las tierras celtíberas". fuese Bámbola, donde se levantó el Municipium Augusta Bilbilis.

La publicación por parte de López Sampedro (1968: 143-157) de la Carta Arqueológica del término municipal de Calatayud inicia una nueva fase de los estudios de Valdeherrera, al mencionar los restos arqueológicos aparecidos en el lugar, retomando las citas o descripciones de La Fuente y Landa, dentro de un estudio más general de la Comarca de Calatayud.

Tendremos que esperar a los años ochenta para encontrar los primeros trabajos monográficos sobre el yacimiento en los que se plantea la adscripción celtíbero-romana del yacimiento (Galindo, 1980; Lostal, 1980; Domínguez, 1983; Galindo y Domínguez, 1985; Domínguez y Galindo, 1984). A partir de entonces Valdeherrera 


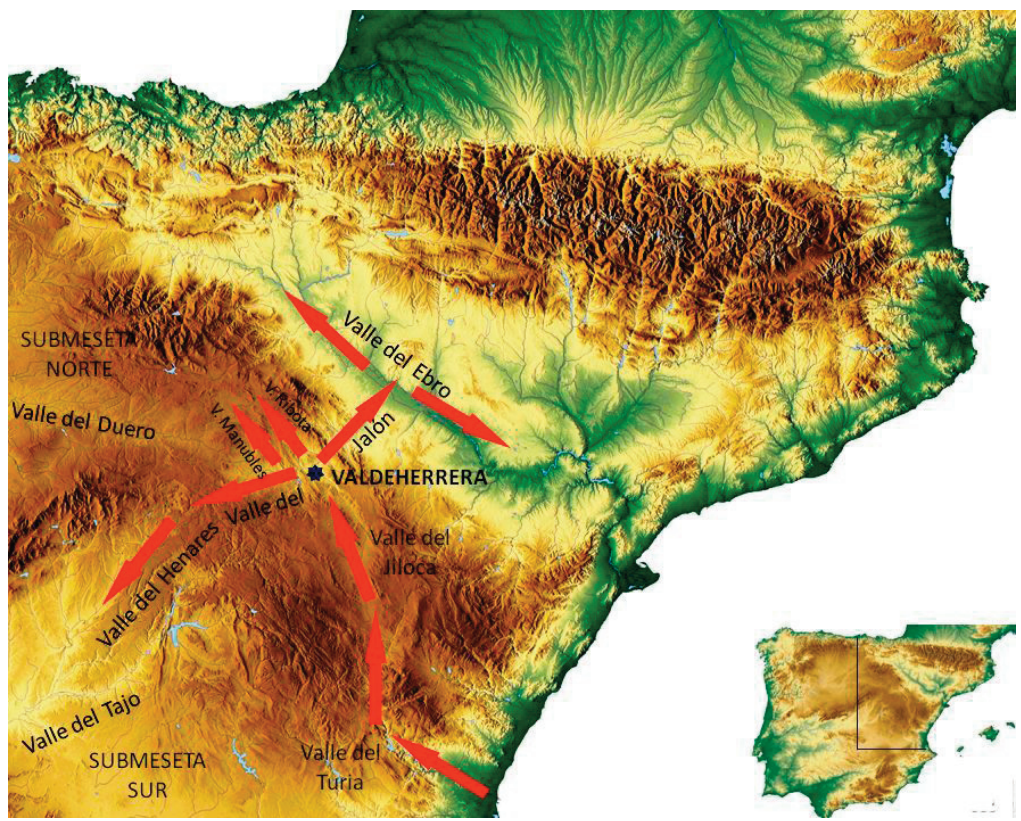

FIG. 3. Situación de Valdeherrera en relación con las principales vias naturales de comunicación de la época de la comarca de Calatayud.

con acuíferos, fuentes o manantiales, ramblas, arroyos o ríos, etc., debido al efecto que el agua ejerce entre los musulmanes como elemento catártico o purificador, que juega un papel fundamental tanto en la vida diaria como en la espiritual a través de su empleo en las abluciones de purificación del cuerpo y la tumba. En este caso basta con recordar la denominación de la zona como 'Cifuentes' para valorar esta relación'.

El yacimiento se encuentra, como anteriormente mencionamos, en el ángulo de confluencia del río Jiloca con el Jalón, siendo visibles ambos ríos y su rica vega, habitualmente inundable, que se extiende hasta los pies del mismo. Por todo ello Valdeherrera reunía bastantes de los requisitos para albergar una maqbara, al ser además habitual su

entra en la historiografía científica como un importante asentamiento en el que ubicar la Bilbilis indígena (Burillo: 1988: 55-57; 1998, 2007; Burillo y Ostalé, 1983-84: 288-303), si bien consideramos que este planteamiento es erróneo (Martín-Bueno y Sáenz, 2003: 357-360; Sáenz et al., 2009: 52-59).

Finalmente queremos reseñar que en ninguno de los trabajos anteriores, ni entre los elementos muebles publicados y conocidos hasta el momento, se han encontrado elementos islámicos, ni siquiera numismáticos de los que el yacimiento es tan prolífico (Martín-Bueno y Redondo, 1979; Domínguez y Galindo, 1984: 63-103, etc.).

\section{La maqbara de Valdeherrera}

\subsection{Ubicación}

La maqbara de Valdeherrera se sitúa al $s$ del yacimiento, extendiéndose por la calle $\mathrm{N}$ y las estancias próximas a estas, pertenecientes a las ínsulas I y II (Fig. 4). La elección del lugar parece estar influenciada por la cercana presencia del agua, ya que en ocasiones las maqabir están relacionadas ubicación en laderas o pequeños altozanos que dominan ríos o ramblas.

${ }^{5}$ En la historiografía moderna se ha generalizado la denominación del lugar en el que se ubica el yacimiento como Valdeherrera, al ser designado así en el Polígono Catastral (P. 31); sin embargo, en realidad el lugar siempre se ha denominado 'Cifuentes', término o denominación ya mencionada, por ejemplo, por López Landa (1935: 71 72): ..."Platea no había de ser una excepción: fue fundada a la orilla del Jiloca muy cerca de su confluencia con el Jalón, en el término que después fue llamado Cifuentes (cien fuentes) por la abundancia de sus manantiales"... y por Rubio Vergara (1952: 35-36) ... "No lejos de la confluencia del Jalón y el Jiloca, en el término de Cifuentes, existió la localidad romana de Platea, sonora por el hierro de sus fundiciones". A pesar de estas citas hay que señalar que La Fuente en 1880 en su Historia de la siempre augusta y fidelísima ciudad de Calatayud se refiere al término como 'Val de Herrera' en el siguiente párrafo: "Los romanos, tan aficionados á utilizar las confluencias de los ríos, no dejarían de aprovechar la del Giloca con el Jalón. En el término de Val de Herrera se ha hallado, y aun a veces se descubren vestigios de edificios antiguos que los labradores destruyen como obstáculo a sus labores...”. Evidentemente hay que reconocer una cierta confusión en la denominación del lugar, pero los agricultores de la zona, especialmente los mayores, se refieren a este lugar como 'Cifuentes', el nombre tradicional, mientras que los jóvenes usan 'Valdeherrera', la denominación catastral. 


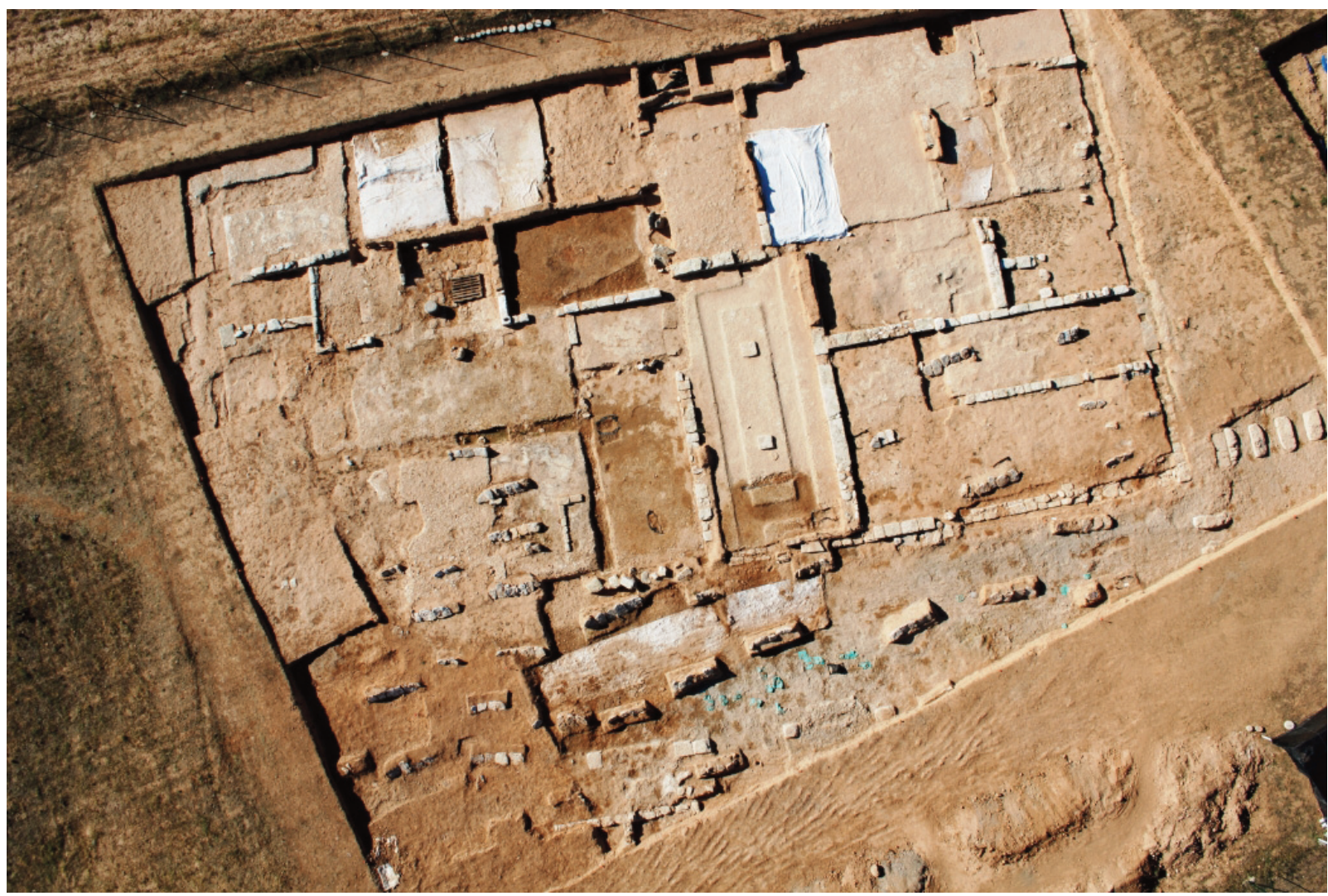

FIG. 4. Vista aérea del sector excavado en la Parcela 296 una vez finalizada la campaña de 2011 (fotog. de. L. Lanteri y C. Vaccarella).

A pesar de ello, pensamos que la necrópolis está vinculada a un asentamiento temporal islámico que parece responder a razones estratégicas debido al control territorial que se ejercía desde este pequeño altozano desde donde se divisaba y controlaba perfectamente Calatayud, así como las rutas del Jiloca y el Jalón. Por otra parte, la presencia de los potentes fosos que circundaron la ciudad celtibérica en tres de sus lados y el cortado oriental, le proporcionaban un carácter inexpugnable y seguro para el asentamiento temporal musulmán y, por extensión, debido a la amplitud de la planicie existente de aproximadamente 35 ha, para la ubicación del cementerio ${ }^{6}$.

${ }^{6}$ La extensión del yacimiento, fosos y recinto amurallado se documentan en Martín-Bueno y Sáenz, 2009: 429-437; 2012: 11-17.

\subsection{Descripción de la maqbara}

Hasta el momento (campaña 2012) se han localizado 62 tumbas individuales ${ }^{7}$ (Fig. 5), según marcan los preceptos religiosos, siendo simples fosas de unos 40 o $50 \mathrm{~cm}$ de anchura abiertas en los niveles de destrucción y abandono de las viviendas de la ciudad sertoriana, llegando a perforar en algunos casos los pavimentos de mortero blanco de las estancias como en el caso de las tumbas T. 6, T. 17 y T. 18 (Figs. 5 y 9), sin que las tumbas situadas en la calle llegasen a perforar su firme formado con grava apelmazada.

7 Hay ausencia de osarios, algo lógico al estar estos prohibidos (Dickie, 1985: 46), aunque se han podido constatar algunos casos excepcionales, como en la maqbara de Madinat Baguh en Priego, Córdoba (Carmona y Luna, 1996: 121). 


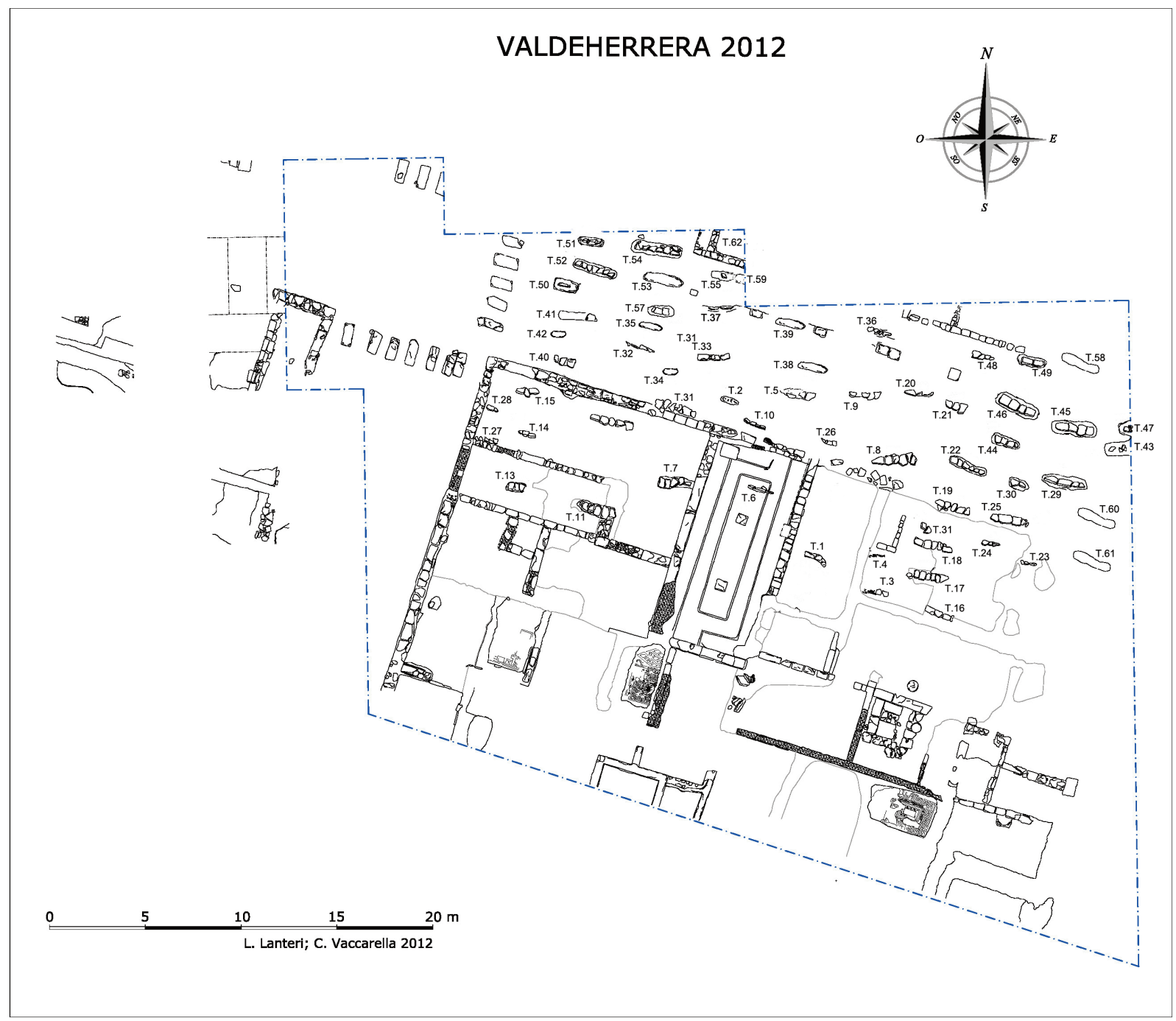

Fig. 5. Planimetría del sector excavado en la Parcela 296 una vez finalizada la campaña de 2012 (L. Lanteri y C. Vaccarella).

La necrópolis se encuentra perfectamente organizada en un espacio abierto, como en la mayoría de las maqabir peninsulares, sin cercados o delimitaciones que la circunden (Figs. 6 y 7). Bien es cierto que, a falta de una visión global, la zona excavada nos es suficiente para apreciar una organización espacial preestablecida mediante sepulturas alineadas que configuran calles paralelas de circulación por las que transitarían los cortejos funerarios y los visitantes, siendo esta una tónica bastante habitual como se ha podido apreciar en el Tossal de
Manises (Alicante) (Tendero et al., 2007: 139, fig. 3.49), en la fase primera de la necrópolis de Roteros de Valencia (Pascual y Serrano, 1996: 234), Marroquíes Bajos en Jaén (Serrano y Castillo, 2000: 106), Calatrava la Vieja (Ciudad Real) (Prieto et al., 1988: 127), etc.

\subsubsection{Las tumbas}

La maqbara de Valdeherrera presenta unos enterramientos que responden a un esquema 
sobrio y sencillo ${ }^{8}$, siguiendo la doctrina maliki ampliamente difundida en al-Andalus que estableció una serie de rituales y normas vinculados con ella ${ }^{9}$ que censuran y desaprueban las tumbas monumentales y promueve que fuesen estrechas, excavadas en la misma tierra y "no más profundas que la cintura de un hombre", sin obra alguna. Los cubrimientos son sencillos, a lo sumo una simple cubierta de madera, lajas o tejas, sobre la que se dispone un túmulo de tierra a modo de única señalización externa de la tumba. Se observa una gran homogeneidad tipológica y una total ausencia de otros elementos

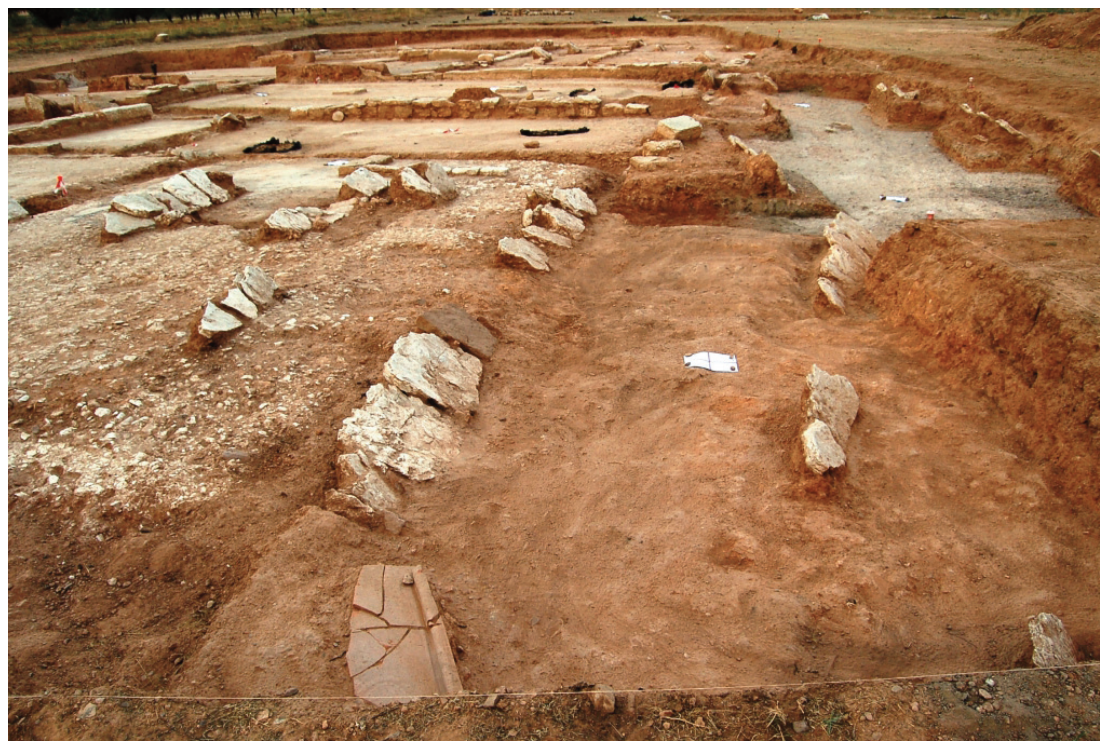

FIG. 6. Detalle de la necrópolis medieval islámica donde se aprecia el alineamiento de las tumbas en hileras paralelas. estelas, etc. De esta manera se mantienen los preceptos de igualdad social y económica que deben tener los enterrados y sus tumbas.

${ }^{8}$ El estudio de las necrópolis musulmanas de al-Andalus permite apreciar cómo la ceremonia y el ritual de enterramiento son fieles a la shariqa, salvo los lógicos cambios, por otra parte apenas perceptibles, explicables por la evolución del ritual, así como, las más de las veces, por los condicionamientos físicos del terreno y del entorno en donde se ubique la necrópolis (Roselló, 1992: 162).

${ }^{9}$ El inicio de la presencia omeya en la Península vino marcado por la influencia de al-Awzai (Damasco, 87/704Beirut, 157/774) uno de los máximos representantes de la escuela siria de derecho religioso, cuyos discípulos expandieron sus doctrinas por el Magreb y al-Andalus influyendo notablemente en los ulemas andalusíes de ciudades como Córdoba, Toledo, Saraqusta. A pesar de ello, la llegada a la Península Ibérica de discípulos de Málik bin Anas (708/716-796), cuyo nacimiento supuestamente fue predicho por Mahoma, supuso una profunda transformación del pensamiento, pasando a representar la tradición más pura y auténtica desarrollada en torno a las enseñanzas del Profeta, asumiendo desde el rigor el Corán y la sunna como fuentes esenciales del derecho islámico y aceptando los hechos y dichos del profeta y sus compañeros (hadices) como ejemplarizantes. La llegada a Córdoba de los escritos de Malik, especialmente del tratado Kitáb al-Muwattá, supuso una auténtica revolución a la hora de interpretar y seguir el Corán. Esta nueva doctrina y escuela
Respecto a su orientación, si bien se aprecia un respeto a los rígidos preceptos coránicos, observamos una cierta flexibilidad y ligeras variaciones, desviándose ligeramente del tradicional eje NO-SE perpendicular al eje de la qibla y depositando el cuerpo envuelto en un sudario ${ }^{10}$. La orientación de las cabeceras se mantiene en un arco bastante homogéneo entre $285^{\circ}-300^{\circ}$, si exceptuamos las tumbas 5, 8, 9, 13, 20 y 33, que presentan una orientación casi perfecta O-E, pero siempre con el rostro orientado hacia el SE,

de pensamiento - malikí o escuela de Medina-, se difundió rápidamente en al-Andalus, lo que supuso casi una inmediata desaparición de las enseñanzas juristas de alAwzai al ser reemplazadas por el rito maliki, si bien se aprecia como a partir del s. Ix la escuela malikí andalusí renuncia al estudio de los hadices, volviéndose inmovilista al prohibirse la interpretación y la reflexión personal (Arié, 1982: 339-341).

${ }^{10} \mathrm{La}$ tradición recoge la posibilidad de no lavar al difunto cuando este haya fallecido en combate como un mártir, siendo amortajado con su propia ropa, ya que la sangre con la que está empapada es muestra irrefutable de su fe, suponiendo su martirio el perdón de todo pecado (Dickie, 1985: 44). Evidentemente es casi imposible apreciar este hecho en los enterramientos de Valdeherrera, a pesar de atestiguarse indicios de muertes violentas (T. 1, т. 4, т. 6 у т. 46). 


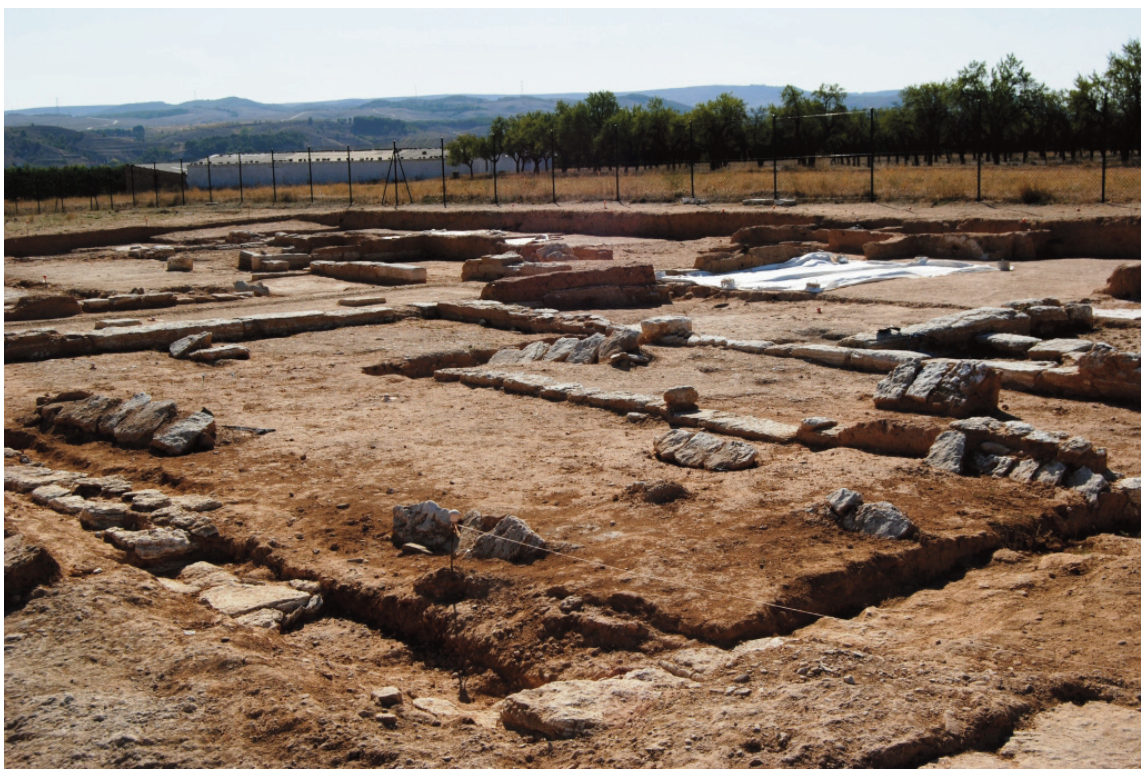

FIG. 7. Tumbas ubicadas en el interior de los espacios privados de la casa 3.

alguno; se cubre con un pequeño túmulo longitudinal formado por la tierra procedente de la excavación de la tumba. Generalmente esta fosa se abre en espacios que presentan pavimentos duros (Fig. 9).

- Fosa alargada con extremos rectos o redondeados y cubierta por tres o cuatro losas de yeso alabastrino colocadas a un agua descendente hacia el $\mathrm{N}$ protegiendo la parte dorsal del cuerpo enterrado (Fig. 10). Estas losas proceden de la partición de los bloques alabastrinos empleados en los zócalos de las viviendas celtibéricas, de

forzándolo si es necesario con la colocación de una piedra que bloquee el cráneo.

Esta orientación parece quedar condicionada por la disposición urbana de la ciudad indígena, ya que la mayor parte de las tumbas se disponen de forma paralela a los muros perimetrales de la insula (O/NO-E/SE), y por extensión de la calle, que determina su disposición que coincida aproximadamente con la orientación buscada marcada por el rito coránico. De ahí que tuviesen en estos muros un elemento guía para su trazado e incluso fuese en algunos de ellos, como por ejemplo en la Tumba 31, empleado el zócalo de sillares a modo de shaq.

Se han podido identificar dos tipos de inhumaciones, excavadas siempre en el terreno, en las que se observa un rito unitario (Fig. 8). En ambos casos la planta de la fosa es longitudinal con extremos rectos o levemente curvos y ligeramente ahusada; la parte inferior es más estrecha para facilitar el encaje del cuerpo que, en ocasiones, puede aparecer calzado con piedras en la espalda para mantener su posición sobre el lateral derecho e inmovilizarlo, especialmente tras el cráneo para asegurar su orientación:

- Fosa alargada con extremos redondeados y paredes rectas, sin enlucido o enfoscado ahí que la ausencia de zócalos y cimentaciones en algunas zonas de la ínsula excava$\mathrm{da}$, especialmente en su zona noreste, sea una consecuencia del expolio y reutilización de los sillares para estos menesteres. En algunos casos se han colocado cuñas o pequeños fragmentos de losas en los huecos que quedaban entre las losas. Posteriormente se cubría la tumba con tierra, quedando visible la cresta de la cubierta. Son muchos los paralelos que encontramos para este tipo de enterramiento a lo largo de alAndalus, variando el tipo de materia empleada para las cubiertas - piedra, ya sean losas o sillarejos, tajas o tegulae reutilizadas, e incluso adobes-.

En nuestro caso no hemos localizado paralelos directos, debido a la peculiaridad del material empleado -losas de yeso alabastrino-, si bien encontramos similitudes formales y cronológicas para el segundo grupo con alguna de las tumbas de las necrópolis del Tolmo de Minateda (Hellín, Albacete), del s. IX (Gutiérrez, 2007: 344); Puerta de Toledo (Zaragoza), fechada por $\mathrm{C}^{14}$ entre el $834 \pm 35$ y $929 \pm 30$ (Galve y Benavente, 1992: 385); Tossal de Manises (Alicante), entre los ss. VIII-X (Tendero et al., 2008: 146-173, fig. 4.3), sin olvidar otras 

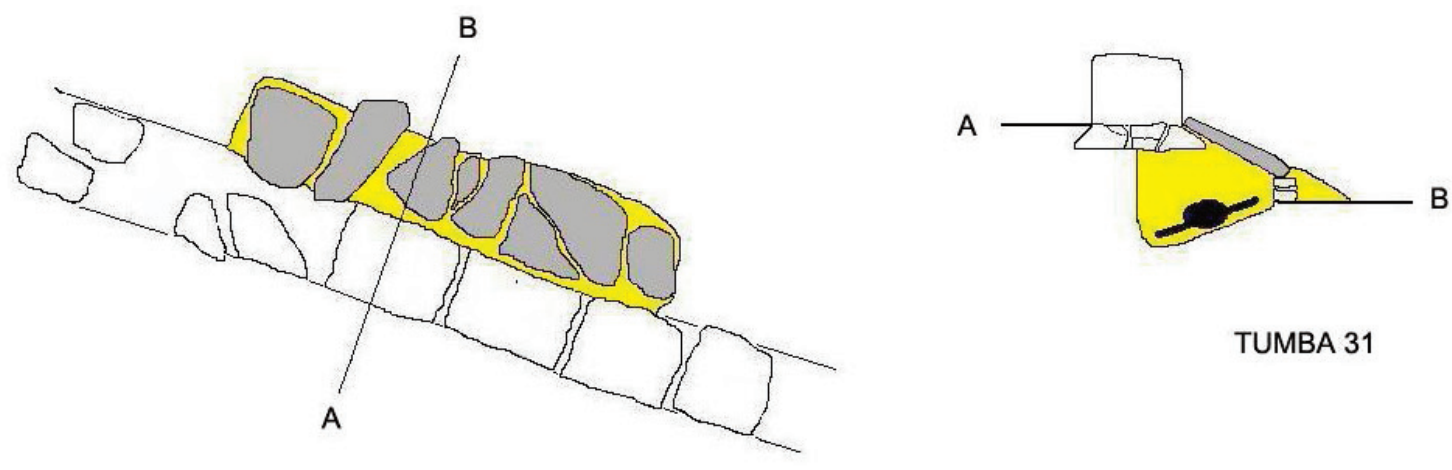

TUMBA 31
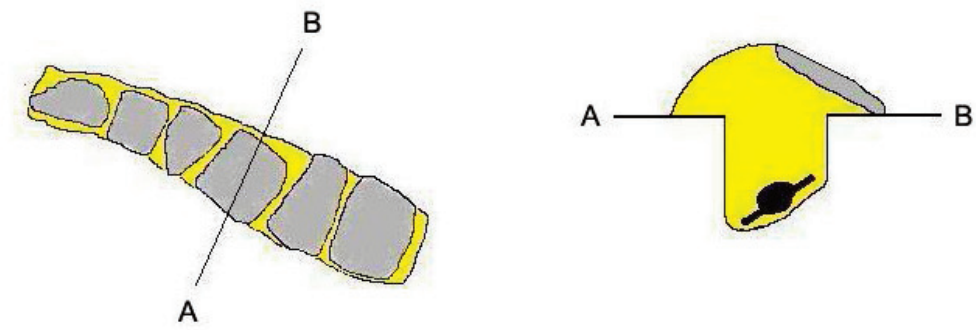

TUMBA 22
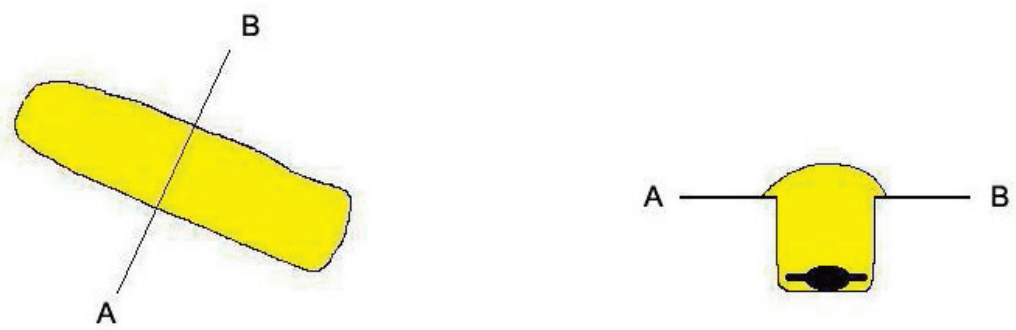

TUMBA 53

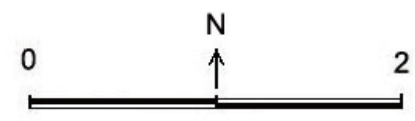

FIG. 8. Tipología de tumbas. 


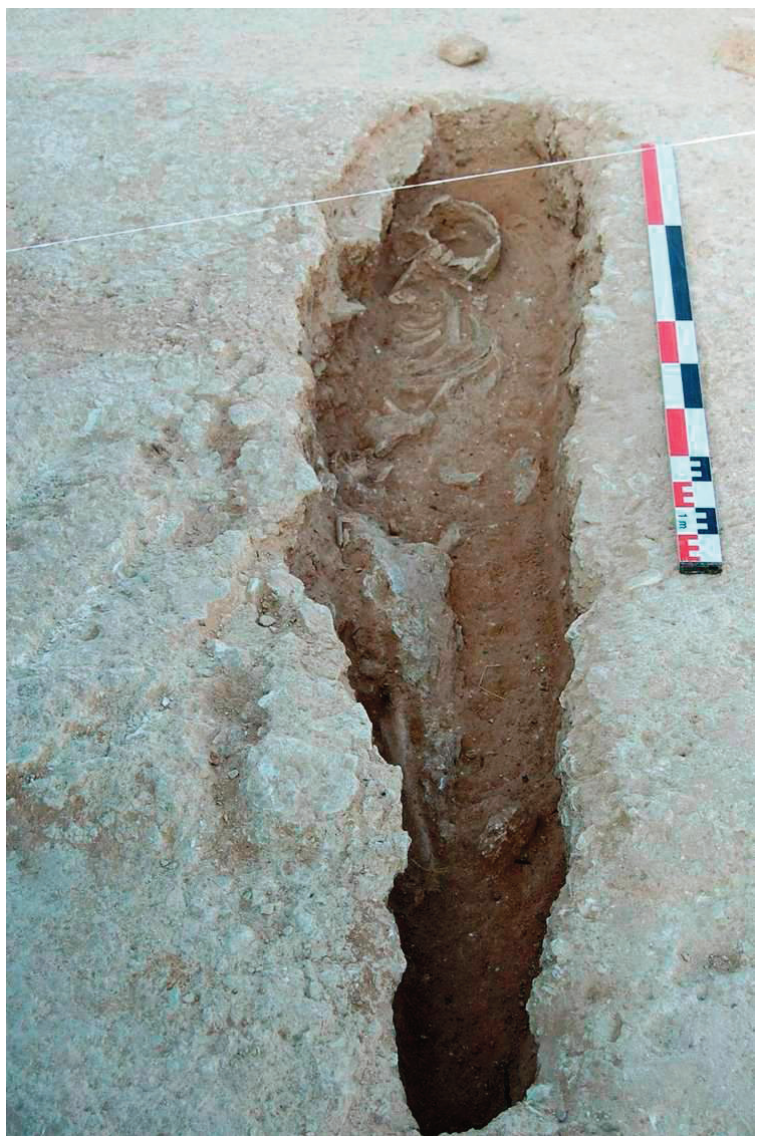

FIG. 9. Tumba T. 6 abierta en el pavimento de mortero blanco del espacio ocupado por el torcularium de la casa 3 .

maqabir como las de Xarea en Vélez Rubio (Haro y Carrión, 1995: 12-16) y el Cerro del Almendralejo en Marbella (Fernández et al., 2001: 618), etc.

Algo muy peculiar de estas fosas es que tienen su lateral oriental recto, mientras que el lateral occidental está algo socavado a modo de covacha, rememorando la tumba del Profeta; donde se colocaba el cuerpo, quedaba apoyada la cadera en la pared, mientras los brazos, cabeza y pecho parecen quedar protegidos por esta pequeña oquedad. Un caso peculiar lo encontramos en la Tumba 31, que se ha sobreexcavado bajo la cimentación de un muro empleándola como cubierta de la covacha (Fig. 11). Es posible que este tipo de pared lateral cóncava debamos ponerlo en relación con la existencia de shaq en tumbas más complejas, siendo una tipología similar a la documentada en las maqabir de Tauste (Zaragoza) ${ }^{11}$ y Ejea de los Caballeros (Zaragoza), Tossal de Manises (Tendero et al., 2008: 146-173), en la necrópolis 4 de Marroquíes Bajos en Jaén (Serrano y Castillo, 2000: 97), etc. En algunos casos la fosa presenta un escalón lateral (Fig. 12) sobre el que apoyar la ya mencionada cubierta.

\subsubsection{La colocación de los cuerpos}

Los cuerpos fueron depositados siguiendo los preceptos coránicos: en posición de decúbito lateral derecho con la cara mirando hacia La Meca, prolongación de la postura del individuo que se coloca de esta manera cuando siente acercarse su fin, a la vez que se comienzan a recitar versículos coránicos $^{12}$.

Los brazos se dispusieron estirados o ligeramente flexionados con las manos apoyadas sobre la pelvis y las piernas rectas o ligeramente flexionadas, apreciándose en su disposición el uso de sudarios que las mantuvieron comprimidas hasta su descomposición. Para asegurar la orientación de la cabeza se dispuso bajo ella un canto rodado o fragmento de sillarejo a modo de "almohadilla", forzándose su orientación para girar el rostro del difunto hacia la qibla. Es interesante reseñar que esta orientación coincide prácticamente con el punto por el que asoma el sol tras la Sierra de Vicor, hecho que debió actuar como un elemento de referencia para la orientación del rostro.

El cuerpo pudo cubrirse con tablas de madera para impedir que la fosa se llenara de tierra. Finalmente se formaba un pequeño túmulo de tierra que cubría el conjunto, y ocupaba toda la prefosa con la tierra extraída.

${ }^{11}$ Aún inédita y en proceso de excavación. Queremos agradecer a F. Gutiérrez, director de las excavaciones, esta información. Para más documentación sobre los trabajos arqueológicos desarrollados en esta necrópolis cf. http://arqueoguti.blogspot.com.es/2010/11/necropolisandalusi-de-tauste-zaragoza.html.

12 ..."Vemos que vuelves tu rostro hacia el cielo. Te dirigimos en una dirección que te agrade. Oriéntate hacia la Mezquita Sagrada”... Los creyentes musulmanes no tienen garantizado el paraíso; la salvación llegará tras un camino de pruebas y valoraciones que se inicia en el momento de la defunción, momento rodeado de lógico dolor, pero también de temor al desconocido más allá y al juicio sobre los actos realizados. 
El estado de conservación de los huesos en general es bastante malo debido a la alta concentración de sales que presenta el terreno fruto de los mampuestos de yesos alabastrinos empleados en la construcción de las estructuras, así como en los pavimentos de opus signinum y de mortero blanco perforados durante la apertura de las fosas de inhumación (Fig. 9). Todo ello obligó a la completa consolidación in situ de los huesos en el momento de su extracción complicando su posterior estudio antropológico.

\subsubsection{Los ajuares}

Hay que señalar la total ausencia de ajuar en el interior de las tumbas y de cualquier otro elemento u objeto ornamental personal que permitiese establecer una determinación cronológica más precisa. También está ausente cualquier hito de señalización o signo de identificación de tipo social, con la sola excepción de los túmulos, siendo esta la norma general de

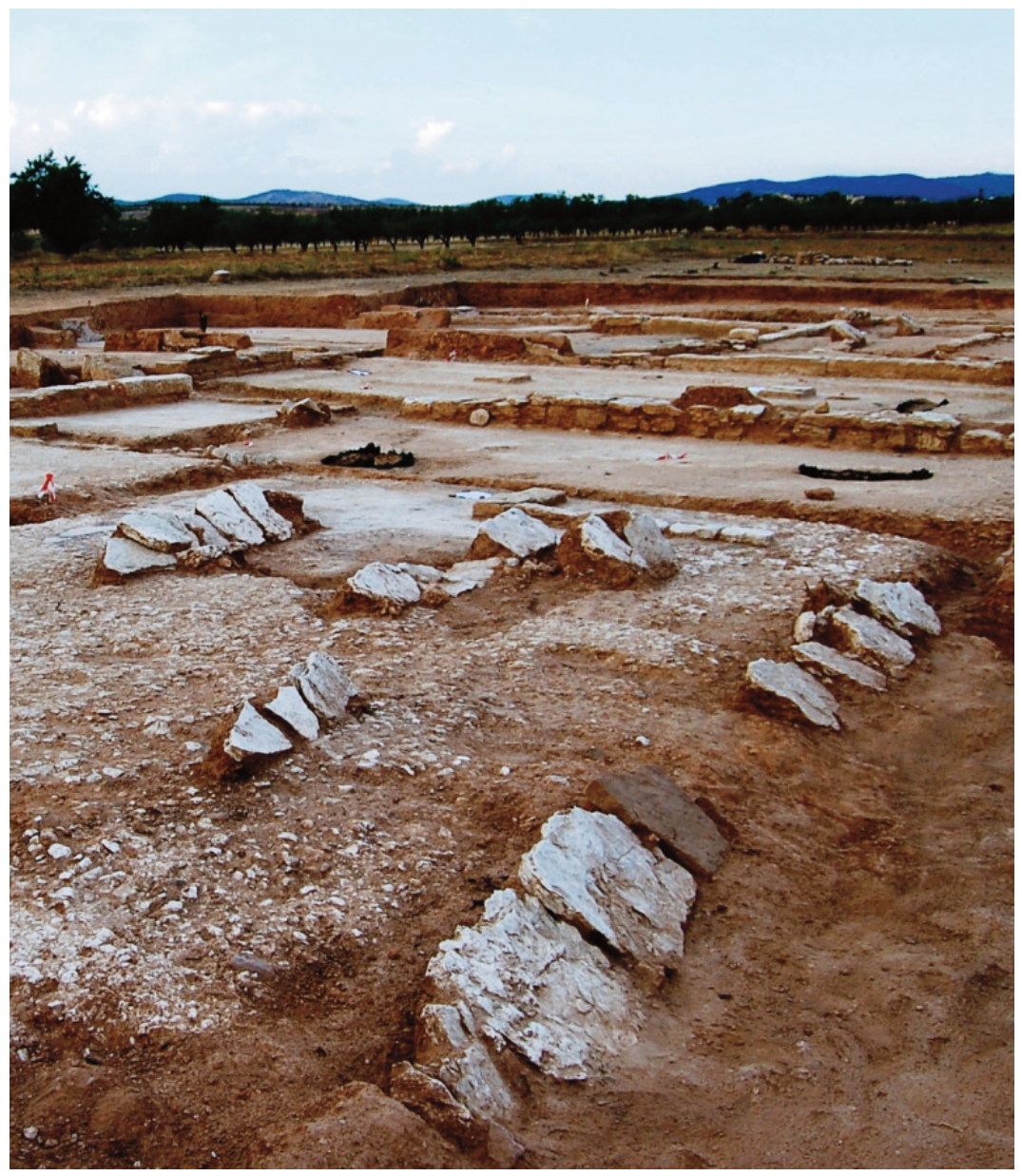

FIG. 10. Concentración de tumbas ( $T$. 16-19 y 24-25) en las que se aprecia la cubierta inclinada de lajas de yeso.

\subsection{Cronología de la maqbara y datación radiocarbónica}

Tras la exhumación de varias tumbas (T. 1, 6, $12,14,19,25,31,35,39$ y 46) y como era de esperar, carecemos de cualquier tipo de material asociado que aportase alguna secuencia cronológica. Por ello se consideró de vital importancia la datación por radiocarbono de algunos restos óseos; se enviaron muestras de las tumbas (T. 21 y T. 46) al Beta Analytic Radiocarbon Dating Laboratory (Miami, Florida-USA), obteniéndose los resultados expresados en la Fig. 13 utilizando la técnica de Espectrometría de Masas con Aceleradores.

Los análisis de $\mathrm{C}^{14}$, una vez calibrado, nos presentan un horizonte que podemos establecer en la 


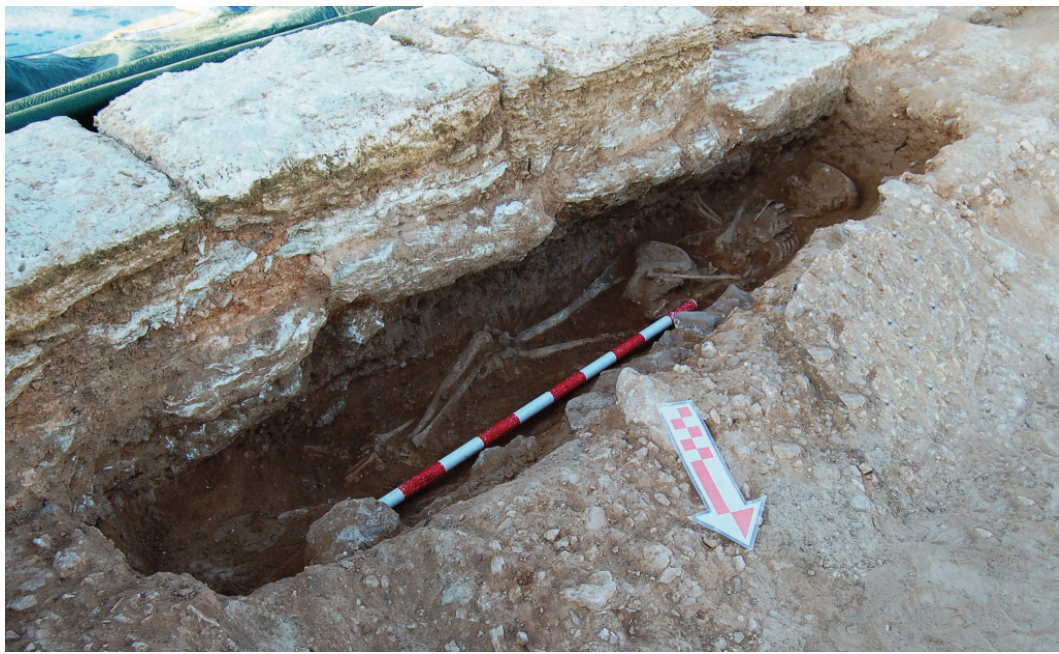

FIG. 11. Tumba 31: el cuerpo se encuentra bajo la cimentación del muro que actúa como cubierta de la oquedad que lo contiene.

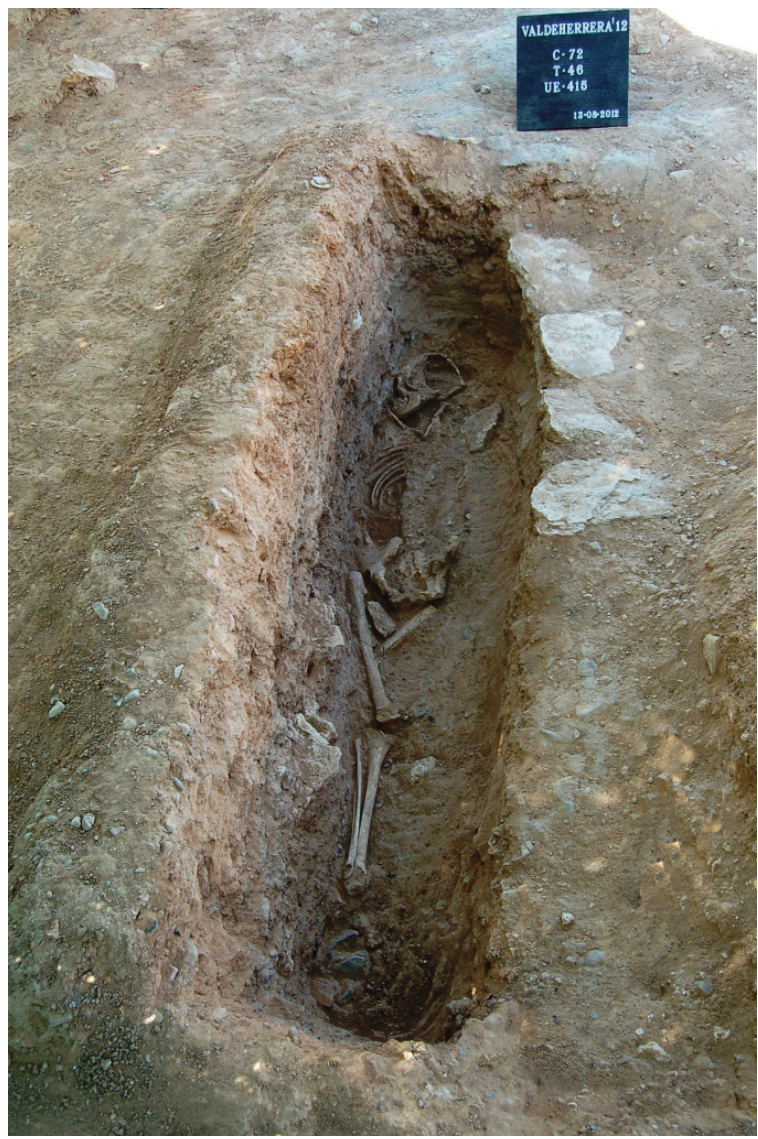

FIG. 12. Tumba 46: se aprecia el escalón lateral reforzado con piedras sobre el que apoyaría la cubierta. segunda mitad del s. IX, más concretamente en sus últimas décadas, debido a lo cual, descartado un asentamiento islámico permanente en Valdeherrera o en su entorno más inmediato al que vincular esta necrópolis, hace que tengamos que ponerla en relación con alguno de los acontecimientos bélicos vinculados con la historia de Calatayud, especialmente con los sucesos derivados del control musulmán de estas tierras y la disputa existente entre sus distintas facciones. No obstante hay que descartar que se trate de una de sus necrópolis, ya que esta se localizó en el sector de la Puerta Terrer conocido también como Puente Seco, fechándose en los ss. X-XII ${ }^{13}$.

\section{La relación entre la maqbara de Valdeherrera y Qal'at Ayyud (Calatayud)}

El paso siguiente fue adscribir esta necrópolis a un núcleo urbano determinado, ya que las áreas funerarias necesariamente estaban cercanas al lugar de hábitat, al no permitir el ritual funerario y sus preceptos largos traslados hasta el lugar del enterramiento (Dickie, 1985: 46).

Ya hemos mencionado cómo en el paraje de Valdeherrera-Cifuentes no existe elemento material alguno de época musulmana. La cercanía de la población de Paracuellos de Jiloca, conocida desde época romana por sus balnearios con aguas sulfurosas e importante asentamiento musulmán que parece identificarse con el Castillo de Xiloca citado

${ }^{13}$ Se trata de una necrópolis descubierta en 2007 cuya excavación puso al descubierto cerca de 250 enterramientos, si bien su extensión debió ser mayor ya que la excavación se limitó a una serie de solares en los que se había previsto la construcción de viviendas. A falta de la publicación de los resultados, a partir de la información dada a conocer por los medios de comunicación, la necrópolis se fecha en los ss. XXII hasta la conquista cristiana de la ciudad, momento en el que la judería se extendió por esta zona, se amplió la barriada hebrea y se construyeron viviendas sobre el cementerio musulmán. 


\begin{tabular}{|c|c|c|c|c|c|c|}
\hline N.o Laboratorio & Enterramiento & $\begin{array}{l}\text { Procedencia } \\
\text { muestras }\end{array}$ & $\begin{array}{c}\text { Calibración } \\
2 \text { sigma }=95 \%\end{array}$ & $\begin{array}{l}\text { Calibración } \\
1 \text { sigma = 68\% }\end{array}$ & $\begin{array}{c}\text { Fecha } \\
\text { radiocarbono } \\
\text { convencional }\end{array}$ & $\begin{array}{l}\text { Fecha Media } \\
\text { Radiocarbono }\end{array}$ \\
\hline Beta (329875) & Tumba 46 & Tibia izquierda & $\begin{array}{l}\text { BP } 1240-1060 \\
\text { AD } 710-890\end{array}$ & $\begin{array}{l}\text { BP } 1180-1070 \\
\text { AD } 770-880\end{array}$ & $\begin{array}{l}\text { BP } 1210 \pm 30 \\
\text { AD } 740 \pm 30\end{array}$ & $\begin{array}{l}\text { BP } 1110 \pm 30 \\
\text { AD } 840 \pm 30\end{array}$ \\
\hline Beta (329876) & Tumba 31 & Cúbito izquierdo & $\begin{array}{l}\text { BP } 1140-1100 \\
\text { AD } 810-850\end{array}$ & $\begin{array}{l}\text { BP } 1060-1050 \\
\text { AD } 880-900\end{array}$ & $\begin{array}{l}\text { BP } 1140 \pm 30 \\
\text { AD } 810 \pm 30\end{array}$ & $\begin{array}{l}\text { BP } 1030 \pm 30 \\
\text { AD } \quad 920 \pm 30\end{array}$ \\
\hline
\end{tabular}

FIG. 13. Resultados de los análisis realizados sobre muestras de las T. 21 y T. 46 mediante Espectrometría de Masas con Aceleradores.

en el Cantar de Mio Cid ${ }^{14}$ y distante tan sólo $3 \mathrm{~km}$ en línea recta, pudiera ser una respuesta, pero debemos descartarla ya que se encuentra en la margen derecha del Jalón, al otro lado de sus vegas y es improbable que la necrópolis de esta localidad se ubicase al otro lado del río. Más cuando sabemos que el ritual exige proximidad entre el lugar de fallecimiento y enterramiento; de ahí deriva la ubicación de las necrópolis en las proximidades de las puertas de las ciudades, como sucede en el caso de la maqbara de la Puerta Terrer de Calatayud.

Su vinculación con otro tipo de hábitat de tipo rural o alquería a modo de pequeña comunidad rural ubicada en Valdeherrera, explotadora de las ricas y fértiles vegas que se extienden en sus inmediaciones, es tentador, pero debemos insistir de nuevo en la inexistencia de cualquier vestigio que pudiera apoyar dicha hipótesis.

Nos queda por lo tanto una única posibilidad, y es que respondiese a una ocupación temporal del lugar. ¿Un campamento militar? Los cuerpos inhumados así parecen indicarlo. La totalidad de los cuerpos exhumados, 12 de las 62 tumbas descubiertas que representan prácticamente el $20 \%$

\footnotetext{
${ }^{14}$ Poco sabemos del Castillo de Xiloca exceptuando que fue conquistado por Alfonso I en 1120 tras la batalla de Cutanda, al mismo tiempo que caía Calatayud y con ella todo el valle del Jiloca. Cuando se formó la Comunidad de aldeas de Daroca se integró en ella formando parte de la sesma del río Jalón, siendo conquistada por los castellanos en 1362 durante la denominada Guerra de los dos Pedros, siendo recuperada por los aragoneses en 1366. El castillo ocupaba una meseta de unos $50 \mathrm{~m}$ de eje mayor en las proximidades de la población, conservándose actualmente escasos restos consistentes en parte de las murallas realizadas en tapial y ladrillo y una torre de planta rectangular, construida en el mismo material que las murallas, que ha perdido el remate (Cabańas, 1999: 133; Guitart, 1976, t. I: 90).
}

de la necrópolis, son hombres adultos, de entre 21 y 40 años, en los que se han documentado muertes violentas con importantes traumatismos como hundimientos craneales en tres casos $-\mathrm{T}$. 4, т. 6 у т. 46- (Fig. 14), sin que en ninguna de ellas se aprecie regeneración ósea; ausencia de extremidades - T. 7 y T. 25-, y puntas de flecha

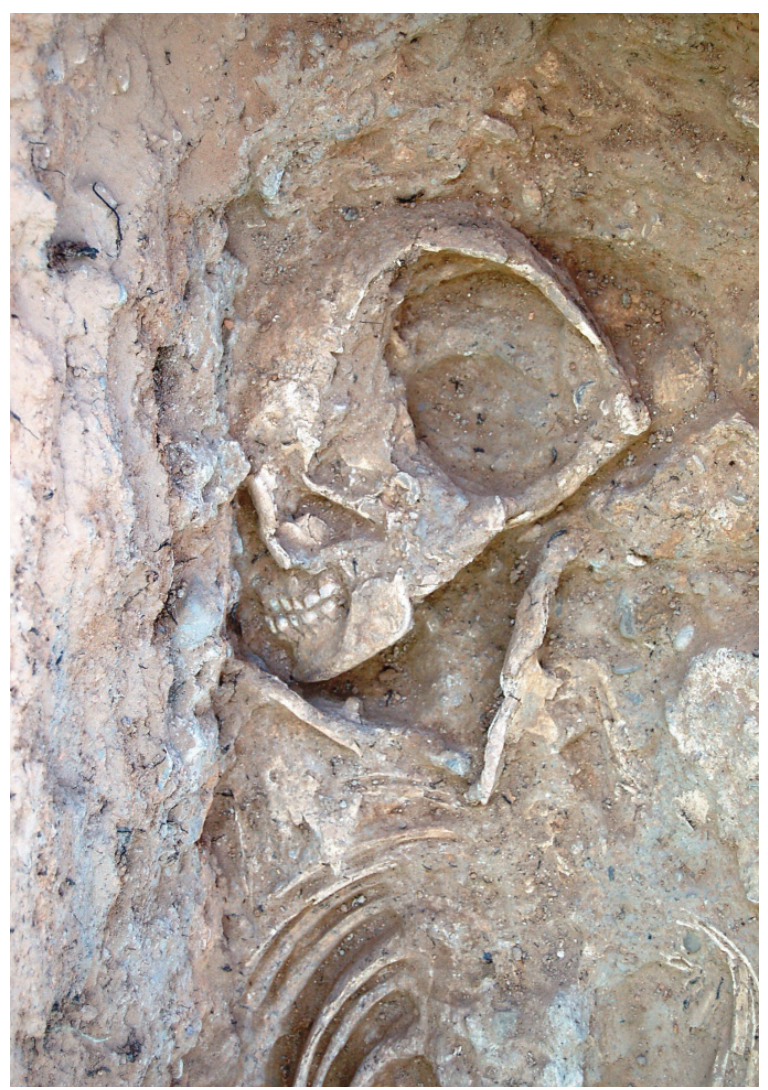

FIG. 14. Tumba 46: el cráneo presenta un fuerte traumatismo y se aprecia el claro hundimiento del parietal izquierdo. 


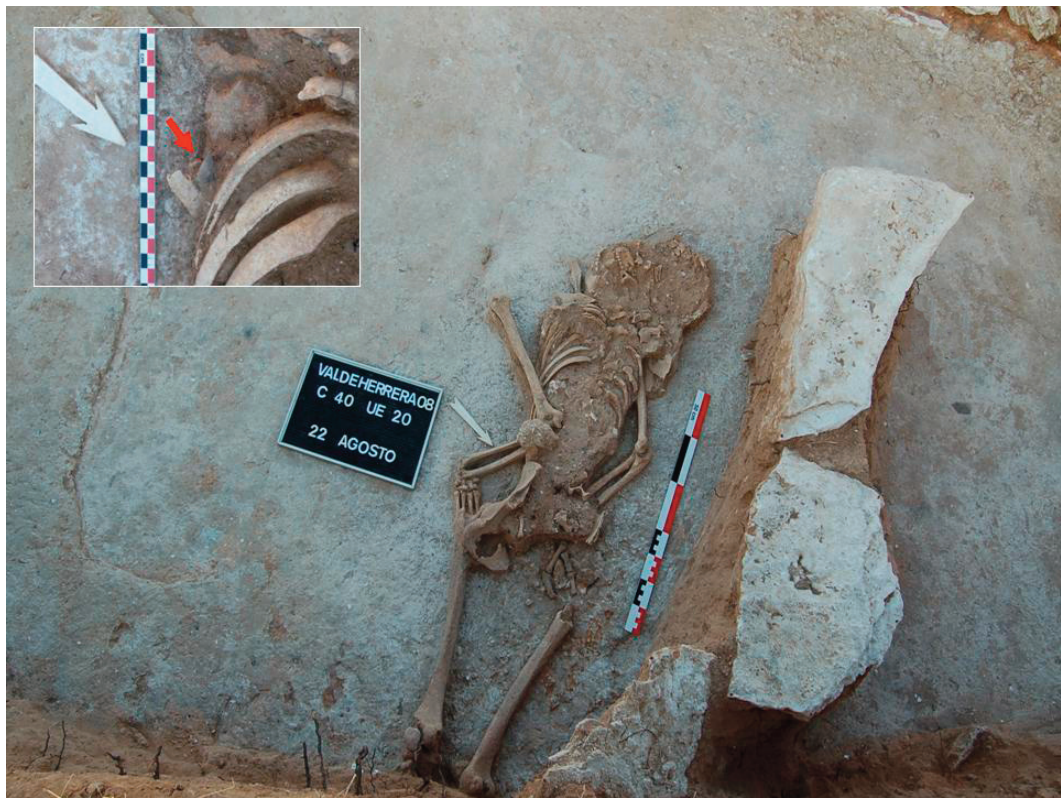

FIG. 15. Tumba 1: es posible observar la punta de flecha clavada entre las costillas.

En el estado actual de la investigación, desconocemos si hubo una presencia u ocupación visigoda en Calatayud, pero podemos intuirla a partir de una serie de hallazgos, principalmente restos de una necrópolis visigoda en el término de Illescas (MartínBueno, 1973: 435-442; Esco, 1987: 633-645). Esta época oscura de Calatayud se rompe con el asentamiento de los musulmanes, al construirse un pequeño qal'a al que se le ańadiría el elemento onomástico de quien tal vez fue su primer sahib o gobernador, de donde se derivaría el topónimo Qal'at Ayyud "Fortaleza de Ayyud", es decir, "Fortaleza de Job", del que resultaría el actual nombre de la ciudad.

No obstante, no sabemos con

incrustadas en los huesos como en el caso del cuerpo de la tumba T. 1 (Fig. 15), en donde se localizó una de ellas entre las costillas.

\section{La fundación de la Calatayud islámica}

Las excavaciones urbanas desarrolladas en Calatayud han permitido constatar la ocupación del lugar ya desde el Bronce antiguo y medio en el denominado Castillo del Reloj (Cebolla et al., 1997: 89-98, láms. 10-12) y en época celtibérica en el Castillo de Doña Martina y su entorno (Royo y Cebolla, 2005: 157-159; Cebolla y Royo, 2006: 281-290).

Las excavaciones también han verificado la presencia de estructuras y elementos muebles de los ss. I-III identificados como pertenecientes a una villa de carácter agrícola (Cebolla et al., 1997: 101-108, 215), a las que hay que añadir la reciente aparición de un importante conjunto termal en la plaza Ballesteros, fechado en los ss. II-IV ${ }^{15}$.

${ }^{15}$ A falta de la publicación de los resultados definitivos de su estudio, parece confirmarse cada vez más la existencia de un importante asentamiento, posiblemente de carácter industrial, tal vez la Platea mencionada por Marcial, dependiente del Municipium Augusta Bilbilis. Si exactitud el momento de dicha fundación, ya que las fuentes árabes no trasmiten noticias de ello ni de ningún otro acontecimiento que se produjese en estos primeros años. Habrá que esperar al emirato de Muhammad I (852-886) y a la crisis o fitna generada por la rebelión de los muladíes para encontrar las primeras menciones de hechos históricos a los que poder vincular la necrópolis de Valdeherrera.

Queda fuera de toda duda, como bien expuso en su momento Souto (1989: 675-696), que debe descartarse la tradición historiográfica, que ha perdurado hasta época bien reciente, de la atribución que Jiménez de Rada hizo en su Historia Arabum ${ }^{16}$ (¿1243-1244?) de la fundación de Calatayud a Ayyub b. Habib en el año $716^{17}$.

bien no se ha podido determinar una significativa ocupación en época bajoimperial, sí podemos establecer que no hay una ruptura en la ocupación del lugar.

${ }^{16}$ Sobre la Historia Arabum cf. Fernández Valverde (1999). Cf. también la Historia Arabum de Jiménez de Rada en la edic. crítica de Lozano (1974, Sevilla).

${ }^{17}$ Tras el asesinato en Sevilla del valí Abd al-Aziz ibn Musa ibn Nusair, casado con Egilona, viuda de Rodrigo en un intento para atraer a la nobleza visigoda, y mientras llegaba desde Qayrawan (Ifriqiya, Túnez) el nombramiento de un nuevo gobernador, Ayyub b. Habib al-Lajmi 
Será Zurita quien termine por generalizar esta atribución: "Fue poblado este lugar según se escribe en la historia de los árabes en el mismo tiempo que los moros se apoderaron de España; y su poblador fue Ayub, el que volvió la silla real de los árabes a la ciudad de Córdoba"18 (Canellas, 1967: lib. I, cap. XLV, 148), popularizada ampliamente en la historiografía de Calatayud tras el tratado de Martínez del Villar (1598: II, 1-44).

Tendremos que llegar a V. de la Fuente (1994: 114) para encontrar el planteamiento de una duda razonable sobre esta arraigada tradición, si bien no llegó a pronunciarse del todo: ..."es tan inofensiva e insignificante, que no merece la pena de molestarse en sostenerla con calor, y como, por otra parte, los argumentos son negativos, y no presenta documento en contrario, ni noticias de otro origen ni de otra etimología, bien puede continuar, mientras no aparezcan otras mejores".

Ciertamente el topónimo Calatayud-Qal'at Ayyud con Ayyud b. Habib ha quedado como axioma, manteniéndose hasta hoy esta atribución u origen de la ciudad, a pesar de trabajos como los de Souto (1989: 677-680), que recoge los textos del historiador y geógrafo andalusí $A l-U d r i$ (1003-1085) en Tarsi 'al-ajbar, en los que se describe la rebelión en la Marca Superior de los Banu Qasi ${ }^{19}$ contra el imán Muhammad I, quien se vio en la necesidad de llamar a los hijos de Abd al-Azizal-Tuyibi en su ayuda, reconstruyendo para ellos Calatayud, así como Somed, Daroca y Furtis $^{20}$. También le encargó combatir a los Banu

gobernó de manera interina seis meses en 716 actuando como valí de al-Ándalus. Era hijo de una hermana del primer valí y, por tanto, primo hermano del asesinado Musa ibn Nusair. A pesar de ello, como señala Souto (1989: 675-696), esta atribución no resiste una crítica historiográfica rigurosa.

18 Zurita, J. (1562): Anales de la Corona de Aragón. Zaragoza, edic. consultada de Canellas, Zaragoza, $1967-$ 77, lib. I, cap. XLV.

19 Sobre esta familia muladí de origen hispano remitimos a Cañada (1980), Lorenzo (2010) y a su trabajo e. p.: La dawla de los Banu Qasî. Origen, auge y caída de una dinastía muladi en la frontera superior de al-Andalus. Madrid: CSIC.

${ }^{20}$ Hemos manejado las siguientes ediciones y traducciones: Kitab Al-Muqtabis fi tarif riyal al-Andalus edic. de Martínez Antuña: Chronique du règne du calife umayyade
Qasi, poniéndolos al frente de sus gentes, dándoles a cada uno un regalo de cien dinares en cada campaña (TA. 41). En una segunda cita (TA. 49) $A l-U d r i$, refiriéndose a los escritos de $A l-R a z i$ dice: "Cuando se hizo manifiesta hostilidad de los Banu Qasi en la Marca, en Zaragoza, en tiempos del imán Muhammad I, reconstruyó éste la ciudad de Calatayud y dejó en ella a $A b d$ alAziz al-Tuyibi, en el año 248 (7 marzo 862-23 febrero 863)". Posteriormente continúa mencionando como desde Calatayud efectuó ataques contra los Banu Qasi hasta su muerte en el 277 (27 abril 890-14 abril 891).

Tampoco podemos dejar pasar las menciones efectuada por el historiador cordobés Ibn Hayyan (987-1075) en la obra Al-Muqtabis fi Tarikh alAndalus, quien matiza estos aspectos: ..."El emir Muhammad b. 'Abdarrahman fue el primero en hacer señores-clientes a estos Tuyibíes, destacados en la Marca superior, cuando le causaron problemas los Banu Qasi, rebeldes de ella. Preparó contra ellos a estos Tuyibies, los invistió como señoresclientes, los reunió y dispuso como vivienda para ellos la ciudad de Calatayud, en esta marca. La [re]construyó para ellos, la fortaleció e introdujo en ella a su caudillo y notable Abdarrahman $b$. 'Abdal'aziz b. 'Abdallah b. al-Muhayir at-Tuyibi, lo nombró oficialmente sobre sus gentes y ordenó a éstas congregarse en torno a él. [Re]construyó para ellos la fortaleza de Daroca y otras, obsequiándoles con dones y asignándoles suplementos por sus campañas"... Esto tuvo lugar en el año 361 (16 octubre 874-5 octubre 875) (MQ-III, 30) ${ }^{21}$.

Como vemos, las incursiones de los Banu Qasi desde el valle del Ebro obligaron a fortificar y

'Abd Allah à Cordove. Paris, 1937 y Tarsi al akhbar, traduc. de F. de la Granja (1966): "La Marca Superior en la obra de al-Udri". En Estudios de Edad Media de la Corona de Aragón, VIII. Zaragoza, pp. 447-545.

21 En ambos casos la similitud de las citas es evidente al ser tomadas por los historiadores Ibn Hayyan y al-Udri de una misma fuente: la Historia de los reyes de al-Andalus (Ajbār mulūk Al-Andalus) o Crónica del Moro Rasis, tal como se denominó el tratado de Ahmad ibn Muhammad al-Razi (887-955 d. C.) conocido como al-Tariji (el Cronista) o, para los historiadores cristianos, el moro Rasis, que desarrolló su labor literaria en tiempos de Abderramán III y que perteneció a una familia de historiadores andalusíes de la época del emirato y califato de Córdoba que abarcó los ss. IX-X. 


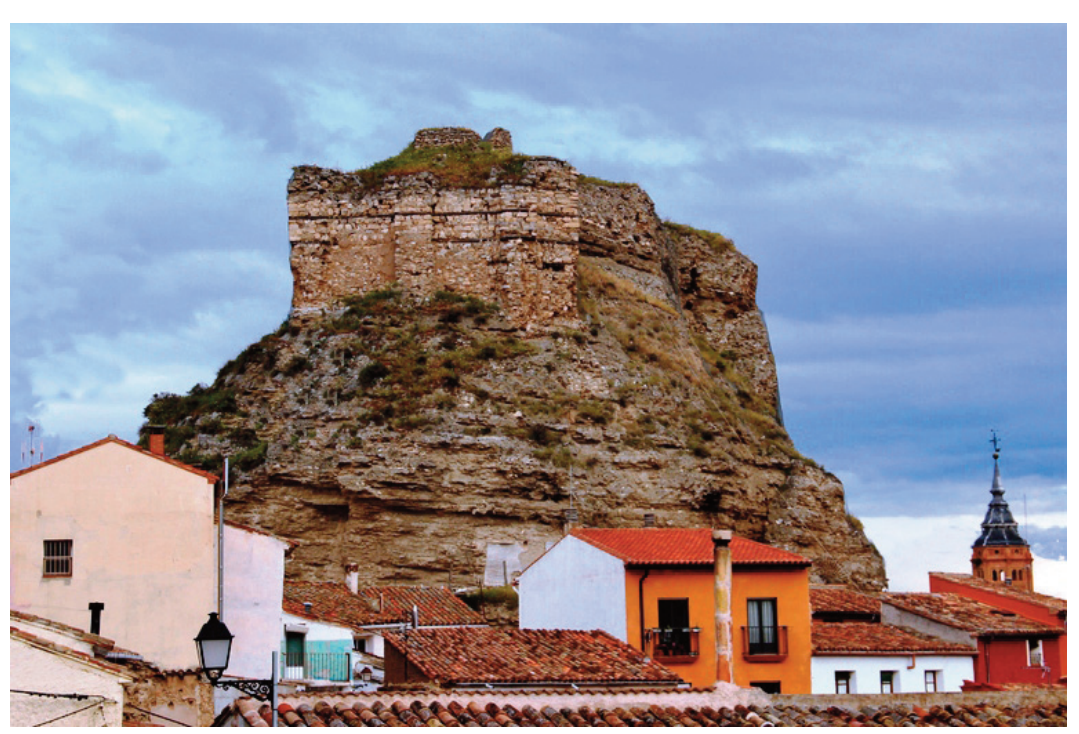

FIG. 16. Castillo de Don Álvaro o Doña Martina en Calatayud. a la interpretación del verbo banà que aparece recogido en los textos anteriores y que puede ser traducido como construir o reconstruir indistintamente. Dice Souto: "Se trata sin duda de uno de los vocablos más incómodos con que se puede encontrar el investigador a la hora de realizar el estudio crítico de una cita, pues significa a la vez construir y reconstruir. El mismo problema presentan sus nombres de acción binà y bunyan que tanto pueden significar 'construcción' como 'reconstrucción' o 'restauración'. Su traducción ha de hacerse teniendo esto en cuenta, y los pasajes en los que figuran estas palabras han poblar la tierra de la comarca de Calatayud con el clan yemení de los tuyubies, establecidos en la Marca Superior y fieles a los omeyas. Abdarrahman b. 'Abdal 'aziz b. al-Muhayir at-Tuyibi convirtió el viejo qal'a en una medina, creando un amplio sistema defensivo en la comarca con la creación de varios husun y sus consiguientes poblaciones (Somed, Daroca, Furtish, etc.). De cualquier manera, los datos que se desprenden de las fuentes escritas no son concluyentes, ya que la fortificación de las tierras de Calatayud y Daroca es una información transmitida por Ahmad ibn Muhammad al-Razi a partir de los escritos de alUdhi, que la sitúan en el 862/863 y los de $I b n$ Hayyan, en el 874/875.

A partir de estos momentos, el poder de los Tuyibies, y por consiguiente el progreso y desarrollo de la medina de Calatayud, fue en aumento, extendiéndose su influencia por gran parte de la Marca Superior y de su capital Saraqusta, donde terminarán por reemplazar a los Banu Qasi, dando lugar con el tiempo a rebeliones contra Córdoba, como la encabezada por Muhammad b. Hashim at'Tuyubi entre 934-937, fundando en el s. XI la primera dinastía de la taifa de Zaragoza.

Antes de continuar debemos hacer una matización que será fundamental a la hora de justificar la necrópolis de Valdeherrera. Para ello reproducimos un texto de Souto (1989: 685, cit. 46) referido de ser considerados con suma cautela, so pena de caer en importantes errores de interpretación. Personalmente, desde hace tiempo nos inclinamos por traducir tales términos anteponiendo el prefijo 're-', encerrado en corchetes, al verbo 'construir' y al sustantivo 'construcción', como se puede ver en este mismo trabajo".

Llegados a este punto podemos vincular la necrópolis, teniendo en cuenta la datación aportada por el $\mathrm{C}^{14}$, con los enfrentamientos entre musulmanes por el control de las tierras de la comarca de Calatayud e incluso con la conquista del viejo qal'a, tal vez un pequeño hisn, que con toda probabilidad estuvo ubicado en el cerro que posteriormente albergó el denominado Castillo de Don Álvaro o de Doña Martina (Fig. 16). No hay que olvidar que es el único de los cinco castillos con los que contó la ciudad construido en buena parte con sillares de caliza encintados por un entramado de madera, como se ha conservado en el muro de poniente, siguiendo técnicas constructivas yemeníes (Souto, 2005: 113-116) ${ }^{22}$.

22 Sobre este aspecto queremos hacer una matización: los sillares calizos empleados en su construcción son originarios del teatro de Bilbilis, procedentes mayoritariamente de su scaenae frons (Martín-Bueno y Sáenz, 2010: 243268). Igualmente, el empleo de un encintado de vigas de madera de encina, generalmente ramas o troncos de 
Por todo ello se deduce que la primera fecha concluyente que tenemos para una presencia efectiva de musulmanes en lo que hoy es Calatayud hay que retrasarla hasta la segunda mitad de s. IX, según se desprende de los datos arqueológicas aportados por la necrópolis de Valdeherrera y de la ausencia de otros elementos culturales islámicos que podamos datar en el s. VIII, fechas corroboradas por las fuentes escritas de al-Udhi que la mencionan en el 862/863 y los de Ibn Hayyan en el $874 / 875$. En todo caso nos remite al s. IX en vez de al s. VIII (716), como ha sido mantenido tradicionalmente hasta ahora.

Si hubo un pequeño qal'a o hisn en lo que hoy es el Castillo de Dońa Martina, no podemos asegurarlo, más si carecemos de excavaciones. Como hemos visto también, las fuentes escritas islámicas son bastante posteriores a los acontecimientos que narran, en el caso de $A l-U d r i$ dos siglos, a pesar de elaborarse a partir de los tratados de al-Razi, escritos a su vez casi un siglo después de que se produjesen los hechos. Es precisamente aquí en donde hay que valorar el verbo banà que aparece recogido en los textos mencionados y que puede ser traducido indistintamente como construir o reconstruir. El empleo de uno u otro da un distinto significado al texto. Si hay, o no hay, una pequeña fortificación previa a la llegada de los tuyubies para fortificar el territorio y crear un tapón frente a los siempre revoltosos Banu Qasi deberá decirlo la arqueología, pero hasta el momento la presencia más antigua queda documentada en la maqbara de Valdeherrera.

\section{Conclusiones}

Evidentemente queda todavía mucho por investigar en el ámbito de la arqueología medieval de Calatayud y su comarca. El descubrimiento de esta maqbara en el transcurso de la excavación

pequeña sección, que alterna con hiladas de sillares dispuestos a soga, está presente en los edificios públicos y privados de Bilbilis. De esta manera se refuerza la construcción ya que la piedra usada en las edificaciones bilbilitanas no es de buena calidad, principalmente piedras pizarrosas extraídas in situ, que son bastante quebradizas y generaron en su momento auténticos problemas estructurales en los edificios en las que fueron empleadas. de Valdeherrera ha sido una sorpresa que permite esclarecer un poco el desconocimiento existente y aportar nuevas informaciones sobre la ocupación del territorio en época islámica.

La falta de elementos de cultura material impide ser más concretos, pero los análisis de $\mathrm{C}^{14}$ efectuados han aportado unas fechas, segunda mitad del s. IX, que concuerdan perfectamente con lo que las fuentes escritas musulmanas decían y que, salvo excepciones, no habían sido consideradas, quedando relegadas por una tradición historiográfica errónea.

Desconocemos todavía mucho de esta maqba$r a$, pero el descubrimiento hasta el momento de 62 tumbas, su disposición, tipología y ritual empleado, estrechamente relacionado con la doctrina maliki ampliamente difundida en al-Andalus, entronca perfectamente con necrópolis como las de Tauste, Ejea de los Caballeros, Daroca, Zaragoza, etc., por citar alguna de las más próximas situadas en el valle medio del Ebro y que presentan cronologías similares.

La evidente muerte violenta documentada en la mayor parte de los cuerpos exhumados nos permite incidir en la vinculación de los enterramientos con acontecimientos históricos concretos que hay que relacionar con el emirato de Muhammad I (852-886) y la pérdida del control omeya sobre los territorios periféricos gobernados por 'señores muladíes', descendientes en algunos casos de la nobleza peninsular preexistente, que los gobernaban de manera autónoma. Esta ausencia de autoridad central terminaría por desencadenar la crisis o fitna generada, en nuestro caso, por la rebelión de los siempre levantiscos Banu Qasi, y la necesidad de taponar, controlar y frenar su expansión por el valle del Jalón. Para ello fue necesario acudir al linaje Tuyibi, que posteriormente extendería su poder por toda la Marca Superior hasta crear Mudir I en 1018, debido al hundimiento y descomposición del califato cordobés, la taifa de Zaragoza.

\section{Bibliografía}

ARIÉ, R. (1982): España musulmana (siglos VIII-XV). En LARA, T. (dir.): Historia de España, t. III. Madrid. BuRILlo, F. (1988): "Bilbilis: un nuevo planteamiento para la ubicación de la ciudad celtibérica”. En Celtiberos. Zaragoza, pp. 55-57. 
170 J. Carlos Sáenz Preciado y Manuel Martín-Bueno / La necrópolis musulmana de Valdeherrera (Calatayud, Zaragoza)...

- (1998): Los celtiberos. Etnias y Estados. Barcelona: ed. Crítica.

- (2007; 2. a ed.): Los celtiberos. Etnias y Estados. Barcelona: ed. Crítica.

Cabañas, A. (1999): Aragón, una tierra de castillos. Zaragoza, 1999, p. 133.

CAÑAda, A. (1980): “Los Banu Qasi (714-924)", Príncipe de Viana, 158-159, pp. 5-95.

CARMONA, R. y LunA, D. (1996): "La necrópolis y los arrabales hispanomusulmanes de la Cava: primeros resultados de una excavación arqueológica de urgencia en Madinat Baguh (Priego de Córdoba)", Antiquitas, 7, pp. 115-134.

Cebolla, J. L. y Royo, J. I. (2006): “Bilbilis I: una nueva ciudad celtibérica bajo el casco histórico de Calatayud". En Burillo, F. (ed.): Segeda y su contexto histórico. Entre Catón y Nobilior (del 195 al 153). Zaragoza, pp. 281-290.

Cebolla, J. L.; Royo, J. I. y Rey, J. (1997): La arqueologia urbana en Calatayud. Datos para una sintesis. Calatayud.

Chalmeta, P. (1968): "El Kitab fi ádab al-hisba (Libro del Buen Gobierno del Zoco de al-Saqati)", AlAndalus, XXXII, fasc. 1, pp. 125-162 y 359-397.

Dickie, J. (1985): "Dios y la eternidad: mezquitas, madrasas y tumbas". En Michell, G. (dir.): La arquitectura del mundo islámico. Madrid, 1, pp. 15-47.

Domínguez Arranz, A. y Galindo, M. ${ }^{a}$ P. (1984): "Hallazgos numismáticos en el término de Calatayud". En II Encuentros de Estudios Numismáticos sobre el tema: los hallazgos monetarios 1983. Gaceta Numismática, 74-75, pp. 63-103.

Esco, C. (1987): "Restos de época visigoda procedentes de Calatayud (Zaragoza)". En Homenaje a D. Federico Balaguer Sánchez. Huesca: Instituto de Estudios Altoaragoneses, pp. 633-645.

FernÁndeZ RodrígueZ, L. E.; Cisneros, M.a I.; Navarro, I.; SuÁrez, J. y Salado, J. B. (2001): "Informe de la intervención arqueológica de urgencia en el Cerro del Almendro (Lomo del Espartal). Autopista de la Costa del Sol (Marbella). 1997", Anuario Arqueológico de Andalucía. 1998, III, Actividades de urgencia, vol. 2, pp. 613-624.

FernÁndez Valverde, J. (1999): Corpvs Christianorvm. Continuatio Mediaevalis, LXXIIC, Roderici Ximenii. Opera omnia. Pars III. Historiae minores. Dialogvs libri vite. Turnhout.

Galindo, M. ${ }^{a}$ P. (1980): "Estado actual de la investigación arqueológica en la cuenca media del Jalón". En II Jornadas el estado actual de los estudios sobre Aragón 1979. Huesca, pp. 185-188.

Galindo, M. ${ }^{\text {a }}$ P. y Domínguez ArRanz, A. (1985): "El yacimiento celtíbero-romano de Valdeherrera
(Calatayud-Zaragoza)". En XVII CAN (1983). Zaragoza, pp. 585-597.

Galve, P. (1995): "Necrópolis islámica de la Puerta de Toledo (Zaragoza): nuevas excavaciones". En TORRES, M. ${ }^{a}$ P. y ACIÉN, M. (eds.): Estudios sobre cementerios islámicos andalusies. Málaga, pp. 117-136.

- (1996): Los antecedentes de Caesaraugusta. Estructuras domésticas de Saldvie. Calle Don Juan de Aragón, 9. Zaragoza.

Galve, P. y Benavente, J. A. (1991): "Las necrópolis islámicas de Zaragoza”. En Las necrópolis de Zaragoza. Zaragoza, pp. 85-98.

- (1992): "La necrópolis islámica de la Puerta de Toledo de Zaragoza". En Actas III Congreso de Arqueología Medieval Española (Oviedo, 1989). Oviedo, t. II, pp. 383-390.

Granja, F. DE LA (1966): "La Marca Superior en la obra de al-Udri". En Estudios de Edad Media de la Corona de Aragón, viII. Zaragoza, pp. 447-545.

Guitart, C. (1976): Castillos de Aragón. Zaragoza, t. I. Gutiérrez Lloret, S. (2007): "La islamización de Tudmir. Balance y perspectivas". En SÈNEC, Ph. (ed.): Villa 2. Villes et campagnes de Tarraconainse et d'al-Andalus (VI-XI siècles): la transition. Toulouse, pp. 323-367.

HaRO, M. y CARrión, F. (1999): "Informe de las excavaciones de urgencia en la necrópolis hispanomusulmana de Xarea, Vélez Rubio (Almería)", Anuario Arqueológico de Andalucíal1995, III, Actividades de urgencia, pp. 9-14

Krausz, S.; Mathe, V. y Druez, M. (2012): “Des prospections géophysiques et pedestres sur l'oppidum celtibère de Valdeherrera (Calatayud, Aragón)", Aquitania, 28, pp. 33-50.

LÓPEZ LANDA, J. M.a (1935): Estampas bilbilitanas (monumentos y paisajes), Tipog. "La Academia", Zaragoza.

López SAMPedro, G. (1968): "Para la carta arqueológica del término municipal de Calatayud", Caesaraugusta, 31-32, pp. 143-157.

LORENZO, J. (2010a): "El valle del Ebro a través de los Banù Qasi”. En SÉNAC, Ph. (ed.): Histoire et archéologie des sociétés de la vallée del l'Ebre. Villa, 3. Toulouse, pp. 209-232

- (2010): La dawla de los Banu Qasî. Origen, auge y caída de una dinastía muladí en la frontera superior de al-Andalus. Madrid: CSIC.

Lorrio, A. L. (2005; 2. ${ }^{\text {a }}$ ed.): Los celtíberos. Madrid.

Lostal, J. (1980): Arqueología del Aragón romano. Zaragoza.

ManZANO, E. (1991): La frontera de al-Andalus en la época de los Omeyas. Biblioteca de Historia. Madrid: CSIC. 
Martín-Bueno, M. (1973): "Nuevos restos visigodos en Calatayud". En Estudios de Edad Media de la Corona de Aragón, vol. IX. Zaragoza, pp. 435-442.

Martín-Bueno, M. A. y Redondo, G. (1979): La colección numismática Dominguez del Museo de Calatayud. Papeles Bilbilitanos, I. Calatayud.

Martín-Bueno, M. y SÁEnz, J. C (2003): "El Barrio de las Termas de Bilbilis: insula I, domus 2 y 3", Saldvie, 3, pp. 355-362.

- (2012): "Valdeherrera: la ocupación del territorio en época celtibérica en el valle medio del Jalón", Aquitania, 28, pp. 7-32;

- (2013): "La ciudad celtibérica de Valdeherrera (Calatayud, España)“. En La guerre et ses traces. Conflits et sociétés en Hispanie à l'époque de la conquete romaine (III-I s. av. J.-C.). Bordeaux: Ausonius Édit., pp. 25-53.

Martín-Bueno, M.; Sáenz, J. C.; Krauz, S. y Mathé, V. (2009): "Prospecciones geofísicas en la ciudad celtibérica de Valdeherrera (Calatayud, Zaragoza)", Saldvie, 9, pp. 419-439.

Martín-Bueno, M.; SÁenz, J. C. y Uribe, P. (2004): "Excavaciones arqueológicas en Bilbilis. Informe preliminar de la campaña de 2003”, Saldvie, 4, pp. 473-488.

Martínez Antuña, R. P. M. (1937): Chronique du règne du calife umayyade Abd Allah à Cordove. Paris.

Olcina, M.; Tendero, E. y Guilabert, A. (2008): "La maqbara del Tossal de Manises (Alicante)", Lucentum, XXVII, pp. 213-227.

Pascual, J. y Serrano, M. ${ }^{a}$ L. (1996): "Necrópolis islámicas en la ciudad de Valencia”, Saetabi, 46, pp. 231-252.

Prieto, G.; Martín Flores, A.; Robles, F.; García, I. y Retuerce, M. (1988): "Dos tumbas de la maqbara de Calatrava la Vieja", Boletín de Arqueologia Medieval, 2, pp. 125-135.

Rey, J. y Turmo, A. (1991): "Prospecciones en la concesión minera Mara II: yacimientos prehistóricos y protohistóricos". En Arqueología Aragonesa 19861987, Zaragoza, pp. 389-392.

Roselló, G. (1992): "Almacabras, ritos funerarios y organización social de Al-Andalus". En Actas del II Congreso de Arqueología Medieval Española (Oviedo, 1989). Oviedo, tomo I, pp. 151-168.

Royo, J. I y Cebolla, J. L. (2005): "La búsqueda de la Bilbilis celtibérica". En Celtiberos. Tras la estela de Numancia. Soria, pp. 153-159.

SÁENZ, J. C. (2011): "La ciudad celtibérica de Valdeherrera (Calatayud, Zaragoza)". En VIII Encuentro de Estudios Bilbilitanos (Calatayud, 2010). Calatayud, pp. 361-378.

Sáenz, J. C.; García, O.; Godoy, C.; Guinda, N.; Lasarte, F.; Salas, M. P. y Morales, S. (2009): "Trabajos arqueológicos realizados por la Escuela Taller de Restauración de Aragón II en el yacimiento de Bilbilis (Calatayud-Zaragoza). Campaña 2008", Kausis, 6, pp. 48-60.

SÉNAC, Ph. (2000): La frontière et les hommes (VIIIe-XIIe siècles). Le peuplement musulman au nord de l'Ebre et les débuts de la reconquête aragonaise. Paris: Maisonneuve et Larose édit.

Serrano, J. L. y Castillo, J. C. (2000): "Las necrópolis de Marroquíes Bajos (Jaén). Avance de las investigaciones arqueológicas", Arqueología y Territorio Medieval, 7, pp. 93-120.

Souto, J. A. (1989): "Sobre la génesis de la Calatayud islámica", Aragón en la Edad Media, 8, pp. 675-696.

- (2005): El conjunto fortificado islámico de Calatayud. Serie: Conocer al-Andalus, 2. Zaragoza: Instituto de Estudios Islámicos y del Oriente Próximo.

Tendero, E.; Guilabert, A. y Olcina, M. (2007): La maqbara del Tossal de Manises (Alicante). Tomo 1: Estudio arqueológico. Serie Excavaciones Arqueológicas, 4. Alicante: MARQ.

Vigil-EsCALERA, A. (2009): "Sepulturas, huertos y radiocarbono (siglos VIII-XIII d. C.)". En El proceso de islamización en el medio rural del centro peninsular y otras cuestiones, Studia Historica. Historia Medieval, 27. Salamanca, pp. 97-118. 